\title{
Skeletal And DentoalveolarChanges Seen In Class II Div 1 Mal- Occlusion Cases Treated With Twin Block Appliance- A Cephalometric Study
}

\author{
${ }^{1}$ Dr. SuchitaTarvade (Daokar), ${ }^{2}$ Dr. Sheetal Yamyar, ${ }^{3}$ Dr. Charushila Choudhari, \\ ${ }^{4}$ Dr. Suhas Biday \\ ${ }^{1}$ Professor \& PG guide, CSMSS Dental College \& Hospital, Aurangabad \\ ${ }^{2} P G$ student, CSMSS Dental College \& Hospital, Aurangabad. \\ ${ }^{3} P G$ Student, CSMSS Dental College \& Hospital, Aurangabad \\ ${ }^{4}$ PG Student, CSMSS Dental College \& Hospital, Aurangabad
}

\begin{abstract}
Class II malocclusion is commonly seen problem in orthodontic practice ${ }^{l}$. Its most consistent finding is mandibular skeletal retrusion ${ }^{2}$. .During the last ten years Twinblock developed W.J Clark ${ }^{l}$. Due to its simplicity of construction and less bulkiness, it has gained increased popularity with the patients as well as with the orthodontist. The present studies have been designed to cephalometrically evaluate skeletal and dentoalveolar changes seen with uses of Twinblock appliance in class II malocclusion with deficient mandible. The study was carried out on 12 growing children of Class II div 1 malocclusion in the age group of 9 -13yrs. in present study conclusive evidence of skeletal, dento- alveolar changes leading to correction of class II div 1 malocclusion with Twin block, a functional appliance, has been established
\end{abstract}

\section{Introduction}

Class II malocclusion is commonly seen problem in orthodontic practice ${ }^{1}$. Its most consistent finding is mandibular skeletal retrusion ${ }^{2}$. When there is mandibular retrognathia, forward positioning the mandible during growth spurts is believe to enhance its growth.

Various types of functional appliance e.g. Activator, Bionator, Frankel, Herbst' appliance are used for correction of class II skeletal and occlusal disharmonies ${ }^{1}$.During the last ten years Twinblock developed W.J Clark ${ }^{1}$. Due to its simplicity of construction and less bulkiness, it has gained increased popularity with the patients as well as with the orthodontist. Functional appliances have shown to have various effects on maxilla as well as mandible and also on the dentoalevolar structures ${ }^{3}$.

The present studies have been designed to cephalometrically evaluate skeletal and dentoalveolar changes seen with uses of Twinblock appliance in class II malocclusion with deficient mandible ${ }^{1}$.

\section{Review Of Literature}

In 1998,DavidO.Morris conducted an evaluation of Bass, Bionator and Twin block appliances on hardtissues and demonstrated statistically significant increase in mandibular length suggesting increase in lower anterior facial height.The anterior movement of the mandible was greatest in the twin block group,followed by Bass and Bionator groups.

In 2005, AntanasSidlauskasMedicina,Kaunas studied the effects of the Twin block appliance treatment on skeletal and dento -alveolar changes in class II div I malocclusion. Cephalometric analysis was done and concluded that there is statistically significant in increasing mandibular length in 12 month time period of time.

In 2006,CarlosFores,PaulW.Major conducted a study to evaluate the facial tissue changes after the use of twin block in class II Div I Malocclusion and seen there is soft tissue profile change statistically significant but the magnitude of changes may not be perceived as clinically significant.

In 2006,RituDuggaland Ashok Jena etal evaluated a quantitative and qualitative analysis effects of Twin block in treatment of class II Malocclusion on 28 growing children concluded that there is improvement in skeletal imbalance and soft tissues relationship.

In2011,OmarYaqoob,AndrewT.Diabase conducted a studied on the use of Clark twin block functional appliance with or without an upper labial bow and compared dent alveolar and skeletal changes in two groups concluded there is no influence on dento-alveolar and skeletal changes with added maxillary labial bow but there is effective change in position of mandible with conventional twin block

In 2O12, Sharma AK, Sachdeva conducted a study on 10 growing children of 9-13yrs class II Malocclusion was given twin block and seen significant skeletal and dentoalevolar changes and concluded 
statistically and clinical significant improvement in forward positioning of mandible which improved the profile and facial esthetics

\section{Aims \& Objectives}

The study was conducted with following aims

1.To evaluate role of twin block on skeletal changes.

2.To evaluate the dentoalveolar changes brought out by Twin block.

\section{Materials \& Methods}

The subjects treated with Twinblock appliance were selected from the Department of Orthodontics,CSMSS Dental College and hospital. The study was carried out on 12 growing children of Class II div 1 malocclusion in the age group of $9-13$ yrs.

The inclusion criteria were

1. Growing co-operative patients.

2. Maxilla is normal and mandible is retro gnathic

3. Horizontally growing patients

4. Upright lower incisors.

The Exclusion criteria were

1. Nongrowing patients

2. Non co-operative patients

3. Maxilla and mandible prognathic cases

4. Vertically growing patients

\section{Method}

The present study was carried out in 12 growing children of class 11 division I Malocclusion in the age group of 9- 13yrs. All the patients were treated with Twin Block therapy. Lateral cephalograms were taken at start and at the end of the Twin block Therapy. The tracings were carried out on pre and post lateral cephalograms and checked for following parameters.

1. SNA ANGLE

2. SNB ANGLE

3. ANB ANGLE

4. U1-SN ANGLE

5. UI-ANS-PNS (mm)

6. U6-ANS-PNS (mm)

7. LI-GO-ME ANGLE

8. L1-GO- ME (mm)

9. L6-GO-ME $(\mathrm{mm})$

10. OP-SN ANGLE

11. FHMP ANGLE

12. MAXILLARY LENGTH

13. MANDIBULAR LENGTH

Difference between cephalometric pre-treatment and post treatments was statistically analyzed using students paired t test .The significance of $p$ value was determined. 

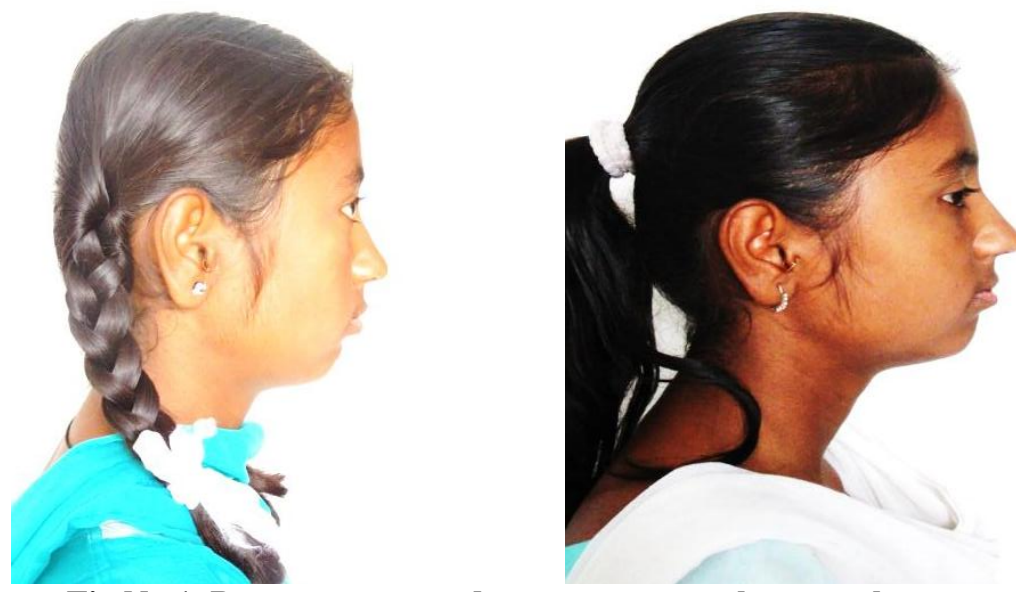

Fig No 1. Pre-treatment and post treatment photographs.

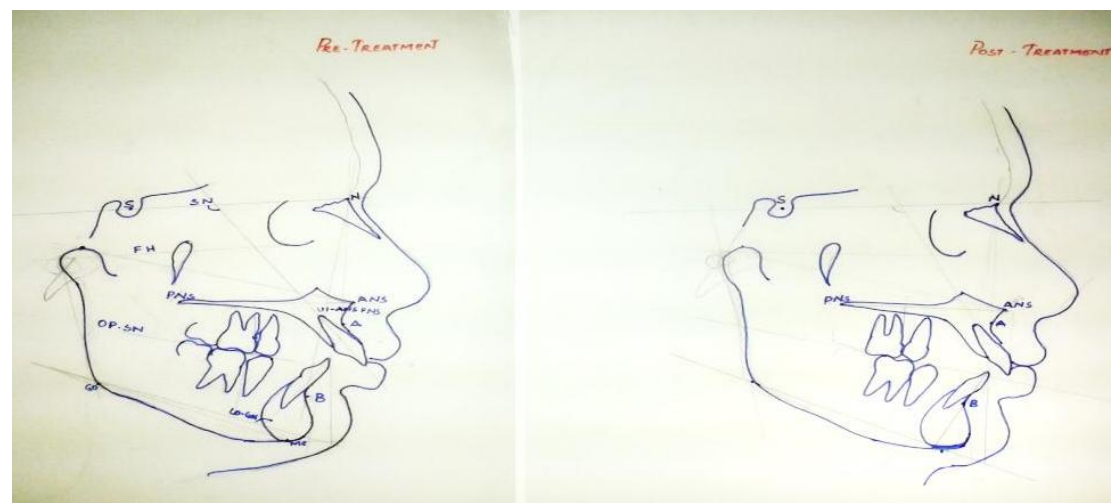

Fig No 2. Pre and post cephalogram tracings

\section{TABLE-I}

\begin{tabular}{|c|c|c|c|c|c|c|c|c|c|c|c|c|c|}
\hline \multirow[t]{2}{*}{ Sr } & \multirow[t]{2}{*}{ SNA } & \multirow[t]{2}{*}{ SNB } & \multirow[t]{2}{*}{ ANB } & \multirow[t]{2}{*}{ U1 -SN } & \multirow{2}{*}{\begin{tabular}{|l|} 
UI \\
ANS
\end{tabular}} & \multirow{2}{*}{$\begin{array}{l}\text { U6 } \\
\text { AN- }\end{array}$} & \multirow{2}{*}{$\begin{array}{l}\text { LO } \\
\text { GO }\end{array}$} & \multicolumn{2}{|c|}{ LI-GO-L6-GO } & \multirow[t]{2}{*}{ OP-SN } & \multirow[t]{2}{*}{ FHMP } & \multirow[t]{2}{*}{ MAX } & \multirow[t]{2}{*}{ MAND } \\
\hline & & & & & & & & ME & ME & & & & \\
\hline 1 & 75 & 71 & 4 & 113 & 27 & 22 & 75 & 40 & 31 & 23 & 32 & 86 & 102 \\
\hline 2 & 84 & 78 & 6 & 101 & 28 & 32 & 76 & 39 & 31 & 18 & 28 & 92 & 109 \\
\hline 3 & 82 & 77 & 5 & 104 & 26 & 22 & 62 & 39 & 31 & 26 & 25 & 88 & 104 \\
\hline 4 & 80 & 76 & 4 & 105 & 29 & 24 & 79 & 42 & 34 & 14 & 26 & 88 & 108 \\
\hline 5 & 84 & 80 & 4 & 110 & 29 & 24 & 78 & 37 & 31 & 18 & 27 & 92 & 114 \\
\hline 6 & 84 & 80 & 4 & 113 & 29 & 22 & 84 & 39 & 30 & 15 & 28 & 85 & 112 \\
\hline 7 & 84 & 80 & 4 & 114 & 26 & 19 & 66 & 39 & 36 & 18 & 30 & 88 & 116 \\
\hline 8 & 82 & 78 & 4 & 115 & 26 & 24 & 75 & 39 & 31 & 18 & 29 & 90 & 106 \\
\hline 9 & 83 & 79 & 4 & 102 & 26 & 24 & 75 & 40 & 31 & 19 & 27 & 86 & 105 \\
\hline 10 & 84 & 80 & 4 & 116 & 27 & 24 & 62 & 42 & 34 & 20 & 26 & 89 & 104 \\
\hline 11 & 79 & 76 & 3 & 114 & 29 & 21 & 83 & 38 & 30 & 19 & 28 & 88 & 105 \\
\hline 12 & 83 & 79 & 4 & 114 & 26 & 22 & 67 & 40 & 30 & 15 & 28 & 92 & 109 \\
\hline MEAN & 82 & 77.83 & 4.17 & 110.08 & 27.33 & 23.33 & 73.50 & 39.50 & \begin{tabular}{|l|}
31.67 \\
\end{tabular} & 18.58 & 27.83 & 88.67 & 107.83 \\
\hline
\end{tabular}

TABLE-2

\begin{tabular}{|c|c|c|c|c|}
\hline & & MEAN & S.D. & $\mathrm{P}$ value \\
\hline \multirow[t]{2}{*}{ SNA } & PRE & 81.66 & 2.46 & \multirow[t]{2}{*}{0.747} \\
\hline & POST & 82 & 2.64 & \\
\hline \multirow[t]{2}{*}{ SNB } & PRE & 75.60 & 2.09 & \multirow[t]{2}{*}{0.032} \\
\hline & POST & 77.8 & 2.51 & \\
\hline \multirow[t]{2}{*}{ ANB } & PRE & 6.0 & 0.20 & \multirow[t]{2}{*}{0.0} \\
\hline & POST & 4.1 & 0.20 & \\
\hline \multirow{2}{*}{ UI-SN1 } & PRE & 114.4 & 7.76 & \multirow[t]{2}{*}{0.120} \\
\hline & POST & $110 . \mathrm{O}$ & 5.27 & \\
\hline \multirow{2}{*}{ U1-ANS -PNS } & PRE & 25.0 & 27.3 & \multirow[t]{2}{*}{0.99} \\
\hline & POST & 25.1 & 1.30 & \\
\hline \multirow[t]{2}{*}{ U6-ANS-PNS } & PRE & 21.58 & 2.01 & \multirow[t]{2}{*}{ O.110 } \\
\hline & POST & 23.33 & 3.00 & \\
\hline \multirow[t]{2}{*}{ L1-GO-ME } & PRE & 38.75 & 1.16 & \multirow[t]{2}{*}{ O.164 } \\
\hline & POST & 39.50 & 1.38 & \\
\hline \multirow[t]{2}{*}{ L6-GO-ME } & PRE & 29.83 & 2.15 & \multirow[t]{2}{*}{0.036} \\
\hline & POST & 31.66 & 1.84 & \\
\hline
\end{tabular}


Skeletal And Dentoalveolar Changes Seen In Class II Div 1 Mal-Occlusion Cases Treated With .....

\begin{tabular}{|c|c|c|c|c|}
\hline \multirow[t]{2}{*}{ OP-SN } & PRE & 21.16 & 2.33 & \multirow[t]{2}{*}{0.036} \\
\hline & POST & 18.58 & 3.22 & \\
\hline \multirow[t]{2}{*}{ FH-MP } & PRE & 25.58 & 1.80 & \multirow[t]{2}{*}{0.036} \\
\hline & POST & 27.83 & 1.81 & \\
\hline \multirow[t]{2}{*}{ MAX-LENGTH } & PRE & 86.83 & 2.22 & \multirow[t]{2}{*}{0.037} \\
\hline & POST & 88.83 & 2.19 & \\
\hline \multirow[t]{2}{*}{ MAND-LENGTH } & PRE & 103.9 & 4.27 & \multirow[t]{2}{*}{0.031} \\
\hline & POST & 107.8 & 4.15 & \\
\hline
\end{tabular}

\section{Results}

SNA Angle- Pre and Post mean value is $81.6 \& 82.0$ and S.D is $\pm 2.46, \pm 2.64$ respectively. When compared applying paired t-test, $p$ value of 0.747 was found which wasstatistically insignificant.

Maxillary Length- Pre and Post mean value is $86.8 \& 88.80$, and S.D is $\pm 2.22, \pm 2.19$ respectively. When compared applying paired t-test, $p$ value of 0.037 was found which is statistically significant.

Studies carried by Antanas showed negative changes with maxillary position denoted by SNA which indicates restrain of the maxilla with Twin block. In our study maxillary length when compared showed significant changes indicating growth of the maxilla was taking place as all the subjects were in growing phase. SNA angle showed positive changes but when compared statistically the results were insignificant indicating that there was headgear effect of Twin block appliance on Maxilla.

SNB Angle- Pre and Post mean value is $75.6 \& 77.0$ and S.D is $\pm 2.09, \pm 2.51$ respectively. When compared applying paired t-test, $\mathrm{p}$ value of 0.032 was found which is statistically significant.

Mandibular Length- Pre and Post mean value is $103.9 \& 107.8$ and S.D is $\pm 4.27, \pm 4.15$ respectively. When compared applying paired t-test, $p$ value of 0.031 was found which wasstatistically significant.

The significant results found in this study indicate that there was a positional as well as changes in the mandibular length.

ANB Angle- Pre and Post mean value is $6.0 \& 4.16$, and S.D is $\pm 0.7, \pm 0.6$ respectively. When compared applying paired t-test, $\mathrm{p}$ value of 0.00 was found which is statistically significant.

The significant changes found in this angle indicate that there is correction of the jaw discrepancy in growing Class II cases treated with Twin Block.

U1-SN Angle- Pre and Post mean value is $114.4 \& 110.0$ and S.D is $\pm 7.76, \pm 5.27$ respectively. When compared applying paired t-test, $p$ value of 0.120 was found which is statistically insignificant.

This angles shows that there was no angular change found in maxillary incisors with the appliance.

U1-ANS-PNS - Pre and Post mean value is $25.0 \& 25.1$, and S.D is $\pm 2.3, \pm 1.30$ respectively. When compared applying paired t-test, $\mathrm{p}$ value of 0.99 was found which is statistically insignificant.

U6-ANS-PNS- Pre and Post mean value is $21.58 \& 23.3$ and S.D is $\pm 2.0, \pm 3.0$ respectively. When compared applying paired t-test, $p$ value of 0.11 was found which is statistically insignificant.

These measurements showed that Twin Block do not lead to any intrusion of the maxillary incisors or molars.

L1-GO-ME Angle- Pre and Post mean value is $77.8 \& 73.5$ and S.D is $\pm 7.34, \pm 7.22$ respectively. When compared applying paired t-test $\mathrm{p}$ value of 0.16 was found which is statistically insignificant.

L1-GO-ME(mm)- Pre and Post mean value is $38.75 \& 39.50$ and S.D is $\pm 1.16, \pm 1.38$ respectively. When compared applying paired t-test, $\mathrm{p}$ value of 0.164 was found which is statistically insignificant.

No changes in lower incisor angulation or inclination were found with Twin Block therapy.

L6-GO-ME(mm)- Pre and Post mean value is $29.83 \& 31.66$ and S.D is $\pm 2.15, \pm 1.84$ respectively. When compared applying paired t-test, $p$ value of 0.036 was found which is statistically significant. There was significant extrusion seen with lower molars along with the therapy. This may result in opening of the bite as well as straightening of the curve of spee.

OP-SN Angle- Pre and Post mean value is $21.16 \& 18.58$ and S.D is $\pm 2.33, \pm 3.22$ respectively. When compared applying paired t-test, $p$ value of 0.036 was found which is statistically significant.

FH-MP Angle- Pre and Post mean value is $25.5 \& 27.8$ and S.D is $\pm 1.8, \pm 1.81$ respectively. When compared applying paired $t$-test $p$ value of 0.006 was found which is statistically significant.

Both these angle showed significant changes indicating growth been redirected in vertical pattern leading to opening of the bite

\section{Discussion}

The most required result of Twin block is a supplementary lengthening of the mandible by stimulating the growth at the condylar cartilage and restriction of the growth of the maxilla.

In our study results reveal significant lengthening of the mandible when the length was measured from Gonion to $(3.8 \mathrm{~mm})$ and changes in SNB angle of $\left(2.2^{0}\right)$. Even though the changes in mandibular length is due to mandibular growth or repositioning of the mandible cannot be confirmed with this study. Antanas in his study 
also found similar results when mandibular length measured from Ar-Pog was compared pre and post. The results were also in accordance with the results of Lund \& Sandler ${ }^{9}$ and Toth\&McNamara.Also maxillary restriction was seen as changes in SNA angle were not satisfactory $\left(0.4^{0}\right)$. These findings were similar to the findings of Antanas ${ }^{1}$. No proclination was seen with lower anteriors in our study where as in Antanas ${ }^{1}$ study proclination of lower incisors of $3.2^{0}$ was seen. Lower molars showed eruption which was significant $\left(0.036^{\circ}\right)$ which again were similar to the findings of Antanas ${ }^{1}$.

Changes in the face were found in the study showing more vertical redirection of growth leading to opening of the SN-OP and FH-MP angle. These results were in accordance to the results found by RituDuggal et al and Sharma et al.

\section{Summary \& Conclusion}

The results found in these studies suggest that:

Twin Block has a headgear effect on maxilla along with its growth acceleration effect on mandible which leads to rapid changes in ANB angle. These changes bring about desirable correction in jaws leading to a change from convex to a more straight profile.

Twin block appliance leads to more clockwise rotation of both maxilla and mandible and also leads to eruption of the lower molar this indicates that the appliance has to be cautiously used in vertical growers.

Thus in present study conclusive evidence of skeletal, dento- alveolar changes leading to correction of class II div 1 malocclusion with Twin block, a functional appliance, has been established. However long termfollow up and studies are recommended with larger sample size.

\section{References}

[1] Antanas,Sidlauaskas: The effects of the Twin -block treatment on skeletal and dentoalveolarchanges in Class II Div I malocclusion. Medicina (Kaunas), 41(5), 2005

[2] SharmaAK,Sachdeva V et al: Skeletal and dentoalveolar changes concurrent to use of Twin block appliance in ClassII division I cases with a deficient mandible:Acephalometric study. Journal of Indian Society of Pedodontics and Preventive Dentistry. Vol 30, Issue 3, Jul-Sep 2012

[3] OmarYaqoob, Andrew $\mathrm{T}$ et al: Use of the Clark Twin block functional appliance with and without an upper labial bow; a randomized controlled trial. Angle orthodontist, Vol 82, No 2, 2012.

[4] HeatherM.Iiing, David et al: A prospective evaluation of bass,bionator, and twin block appliance. Part 1-the hard tissues. European Journal of orthodontist (20),501-518, 1998

[5] Ashok Kumar Jena, RituDuggal: Treatment effects of twin block and mandibular protraction appliance-IV in the correction of class II Malocclusion Angle Orthodontist vol80,no 3, 2010

[6] RituDuggal, Ashok Jena: Quantitive and Quanlitativeeffects of twin block appliances. Journal of Indianorthodontic society. 2006

[7] R.T.Lee,C.S Kyi: A Controlled clinical trial of the effects of the twin block and Dynamax appliances on hard and soft tissues; European journal of orthodontics 29(2007)

[8] McNamara JA: Components of class II malocclusion in children 8-9yrs of age. Angle orthod;51;77-202, 1981

[9] Lund DI, Sandler PJ: The effects of Twin block: a prospective controlled study. American journal of Orthodontic and DentofacialOrthopedics, 113,104-10, 1998.

[10] McNamara JA: Cephalometric diagnosis for functional appliance therapy page no 115 chapter 6 in "Dentofacial Orthopedics with functional appliance" 